\title{
A Modified Design of Phased Array Antenna for UWB5G Cellular Communications
}

\author{
Atta Ullah ${ }^{1}$, Naser Ojaroudi Parchin ${ }^{1}$, Yasir Al-Yasir ${ }^{1}$, Mohammed Bin Melha ${ }^{1}$, Majid Salim \\ Ali Alkhambashi ${ }^{2}$, E. Elkhazmi ${ }^{3}$, and Raed A. Abd-Alhameed ${ }^{1,4}$ \\ \{ A.Ullah5, N.OjaroudiParchin, R.A.A.Abd\} @Bradford.ac.uk \\ ${ }^{1}$ Faculty of Engineering and Informatics, University of Bradford, Bradford BD7 1DP, UK \\ ${ }^{2}$ Sultanat of Oman, Muscat, PO Box 308, Oman \\ ${ }^{3}$ Electronic Technology College, Engineering \& Information Tech Research Center, Bani walid, Libya \\ ${ }^{4}$ Information and Communication Eng. Department, Basrah University College of Science and \\ Technology, Basrah 24001, Iraq
}

\begin{abstract}
In this article, a tiny design of antenna array with ultra-wideband (UWB) function is projected for fifth-generation mobile wireless communications. The array is composed of eight compact modified dipole antenna radiators with directors that have been positioned in a linear form on the top frame of the smartphone mainboard. The functional frequency band of the design expands from 23 to $37.5 \mathrm{GHz}$, providing more than $14 \mathrm{GHz}$ impedance bandwidth. A Rogers RT5880 dielectric with $0.8 \mathrm{~mm}$ thickness, 2.2 dielectric constant, and 0.0009 loss tangent is applied as the design substrate. Important characteristics of the proposed phased array antenna are studied and good results have been acquired. In addition, the array performance in the existence of user-hand is discussed.
\end{abstract}

Keywords: UWB, 5G, dipole antenna, mobile-phone antenna.

\section{Introduction}

$5 \mathrm{G}$ technology can manage more than thousand times more mobile data than earlier mobile wireless transmission networks [1]. The evolution from $4 \mathrm{G}$ to $5 \mathrm{G}$ is predominantly motivated by the mounting need for advanced data rate communications in various appliances such as highquality video streaming [2-3]. In order to provide point to point wireless communication among the user and base station, phased array antenna with compact size and wide bandwidth could be a solution for the future mobile terminals [4-8]. For 5G mobile-phones, compact antennas can be arranged in a linear array form to be working at unique top/bottom segments of a mobilephone $\mathrm{PCB}$. One of the challenges of the antenna design for $5 \mathrm{G}$ mobile-phones is to improve the impedance bandwidth of the employed phased arrays. To address this need, we suggest here a fresh phased array with improved bandwidth. This feature can be achieved by modifying the configurations of the dipole elements to excite the higher modes to increase the operation band of the antenna providing ultra-wideband function [9-11].

Ultra-wideband (UWB) wireless communication technology has gained much attention and became one of the most rapidly developing technologies in wireless applications due to its 
inherently attractive advantages including low power, high transmission rate, and so on [12-15]. Related with other printed microstrip antennas such as monopole, patch, Vivaldi, horn and etc., the dipole is a good option to be used in the ultra-wide-band and point to point communication for wireless systems such as cellular networks [16-17]. Essential features of the designed phased array antenna concerning S-parameters, radiation beams, efficiencies, beam-steering, and gain levels are examined and respectable consequences have been achieved. In addition, the proposed 5G antenna exhibit adequate performance in the surrounding area of the operator-hand at different scanning angles [18]. The antenna element has a compacted size of $\mathrm{W} \times \mathrm{L} \times \mathrm{h}=6.75 \times 4.75 \times 0.8 \mathrm{~mm}^{3}$ and delivers adequate characteristics in terms of radiation patterns, impedance-bandwidth, maximum gain, and efficiencies which have been discussed in Section 2. Section 3 presents the configuration, S-parameters, and radiation beams details of the proposed dipole array. Its effecting in the occurrence of user-hand (data-mode) is described in Section 4. The last Section will conclude this study.

\section{Single-Element UWB Antenna}

Figures 1 (a) and (b) demonstrate the arrangement and simulated $\mathrm{S}_{11}$ result of the solo element, respectively. As demonstrated in Fig. 2 (a), the structure of the projected model is arranged of a modified dipole radiator with a couple of directors. It has a compressed size of $\mathrm{W} \times \mathrm{L}$. The antenna can deliver a UWB operation band. It is seen from Fig. 1 (b) that the antenna element provides more than $14 \mathrm{GHz}$ impedance-bandwidth for $\mathrm{S}_{11} \leq-10 \mathrm{~dB}$ covering different $5 \mathrm{G}$ bands in the mm-wave spectrum [19].

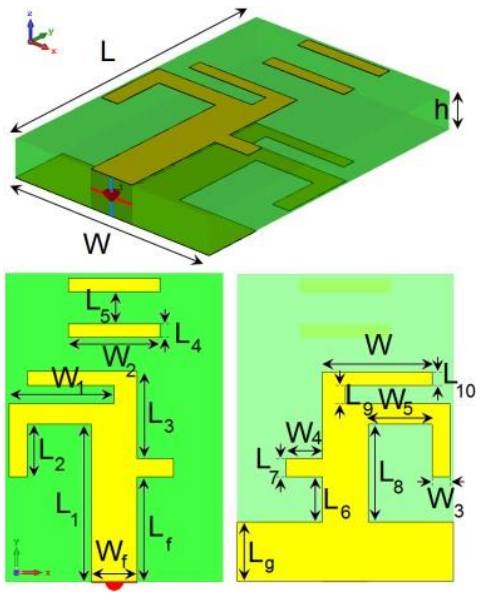

(a)

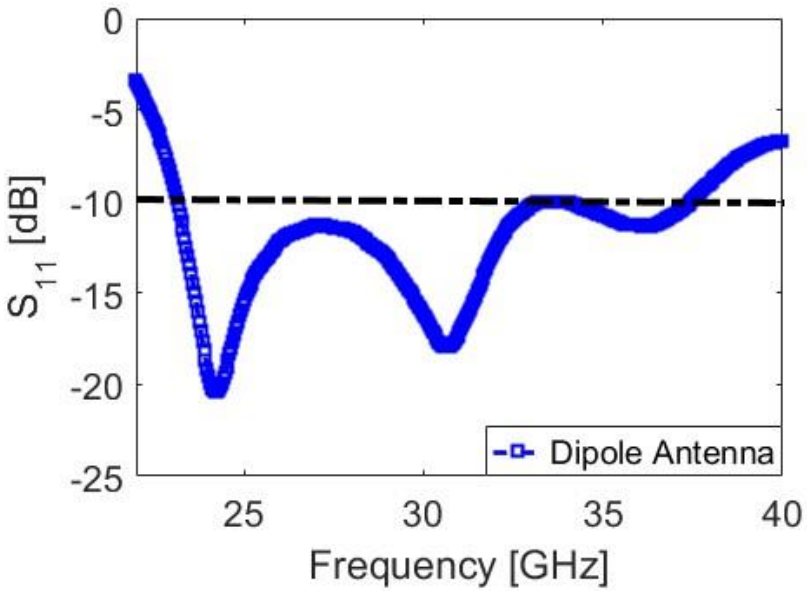

(b)

Fig. 1. (a) Configuration and (b) $S_{11}$ result of the single-element antenna.

Table 1. Final dimensions of the antenna parameters.

\begin{tabular}{|c|c|c|c|c|c|c|c|c|c|c|c|c|}
\hline Parameter & $\mathrm{W}$ & $\mathrm{L}$ & $\mathrm{W}_{\mathrm{f}}$ & $\mathrm{Lf}$ & $\mathrm{Lg}_{\mathrm{g}}$ & $\mathrm{W}_{1}$ & $\mathrm{~W}_{2}$ & $\mathrm{~W}_{3}$ & $\mathrm{~W}_{4}$ & $\mathrm{~W}_{5}$ & $\mathrm{~W}_{\mathrm{a}}$ & $\mathrm{W}_{\mathrm{x}}$ \\
\hline Value $(\mathrm{mm})$ & 6.75 & 4.75 & 1 & 2.3 & 1.3 & 2.3 & 2.9 & 0.4 & 0.8 & 1.4 & 40 & 140 \\
\hline Parameter & $\mathrm{L}_{1}$ & $\mathrm{~L}_{2}$ & $\mathrm{~L}_{3}$ & $\mathrm{~L}_{4}$ & $\mathrm{~L}_{5}$ & $\mathrm{~L}_{6}$ & $\mathrm{~L}_{7}$ & $\mathrm{~L}_{8}$ & $\mathrm{~L}_{9}$ & $\mathrm{~L}_{10}$ & $\mathrm{~L}_{a}$ & $\mathrm{Lx}$ \\
\hline
\end{tabular}




\begin{tabular}{|l|l|l|l|l|l|l|l|l|l|l|l|l|}
\hline Value $(\mathrm{mm})$ & 3.45 & 1.15 & 1.9 & 1.3 & 0.7 & 1 & 0.4 & 2.15 & 0.4 & 0.3 & 6.75 & 70 \\
\hline
\end{tabular}

The antenna radiation pattern in a 3D form at the middle frequency $(30 \mathrm{GHz})$ is depicted in Fig. 3 (a). As can be observed, more than 6 dB IEEE gain with well-defined end-fire mode has been achieved for the antenna radiation pattern [20-21]. The efficiency characteristics of the antenna including radiation and overall efficiencies are plotted in Fig. 5 (b). As shown, the antenna has terrific radiation execution in the frequency scale of 23 to $37.5 \mathrm{GHz}$.

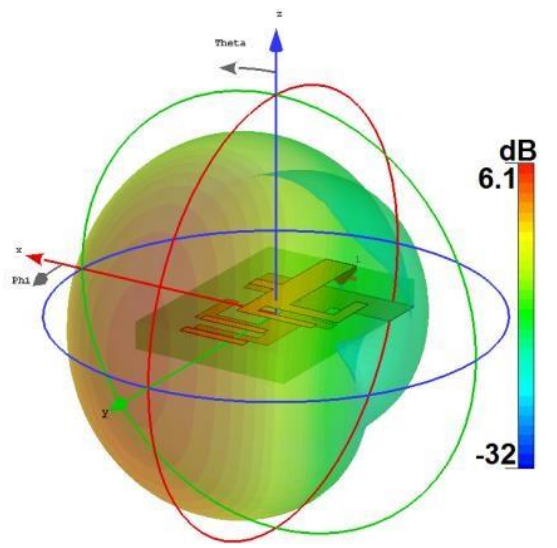

(a)

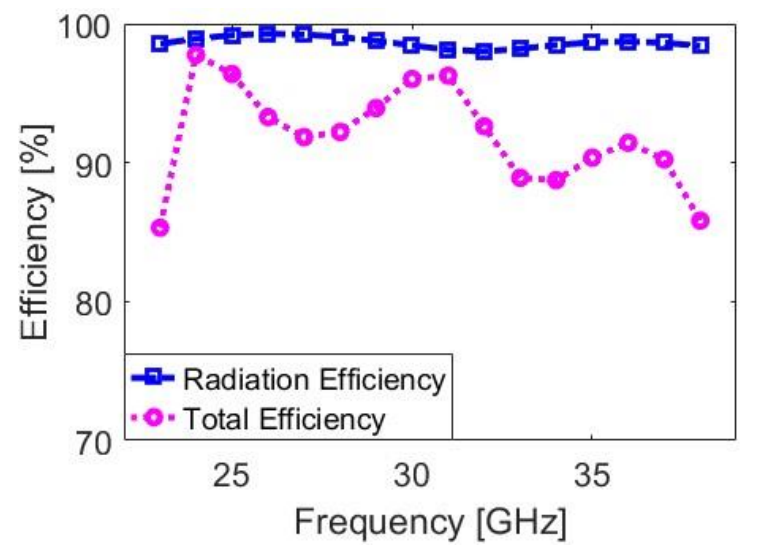

(b)

Fig. 2. (a) Transparent 3D radiation pattern of the antenna at $30 \mathrm{GHz}$ (a) and (b) its efficiency characteristics over the operation band.

\section{The Characteristics of the Array}

The diagram of the antenna array is shown in Fig 3. As it can be detected, eight elements of the designed antennas with end-fire radiation beams have been formed the illustrated array with an overall size of $\mathrm{W}_{\mathrm{a}} \times \mathrm{L}_{\mathrm{a}}$. As mentioned before, the designed phased array has a tiny size which makes it appropriate for use on the top of smartphone mobile PCB. In order to cover the needed beam-scanning of the $5 \mathrm{G}$ cellphone, another set of the array is needed to use at the bottom portion of the PCB [22-24].

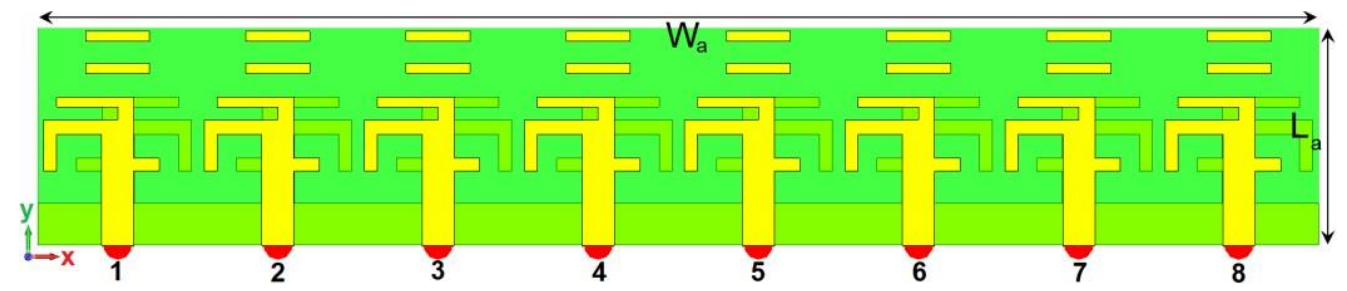

Fig. 3. The graphic of the linear phased array antenna with eight end-fire radiators.

Fig. 4 (a) demonstrates the $\mathrm{S}$ parameters of the array design (for 5G mobile phone). As shown, the antenna is functional at the frequency scale of $23-37.5 \mathrm{GHz}$ (more than $14.5 \mathrm{GHz}$ bandwidth). In addition, there is good isolation between the radiators of the proposed design 
(less than $-12 \mathrm{~dB}$ ) which creates the antenna appropriate for phased array and scanning applications. Figure 7 relates the extreme gains of the antenna aspect and the main design over the operating frequency range. It is demonstrated that the antenna component can provide 4.5 6.5 dBi maximum gain at the frequency range of $23 \sim 37.5 \mathrm{GHz}$.

In addition, the designed array exhibits sufficient and high maximum gain characteristics with values of 10.5-14.5 d|Bi over the antenna operation band [25-27]. It was also found that the high gain levels of the designs have been developed with the increasing frequency. In order to establish the adequate characteristics of the projected phased array across its operation bands, the focal radiation beams $\left(0^{\circ}\right)$ of the phased array model at selected frequencies over its operating frequency band are represented in Fig. 5. It is obvious that the projected layout delivers terrific radiation beams with superior gain characteristics at various frequencies.

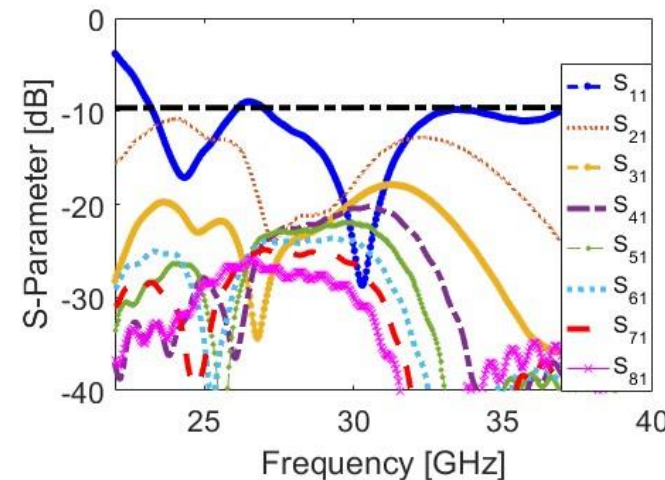

(a)

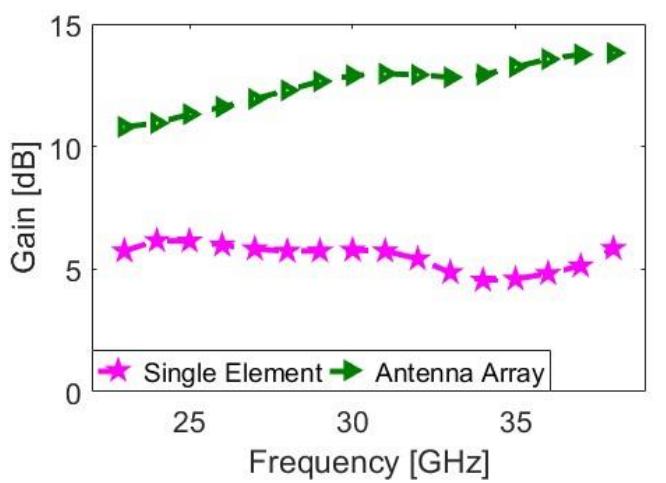

(b)

Fig. 4. Transparent (a) side and (b) top views of the proposed monopole antenna design.

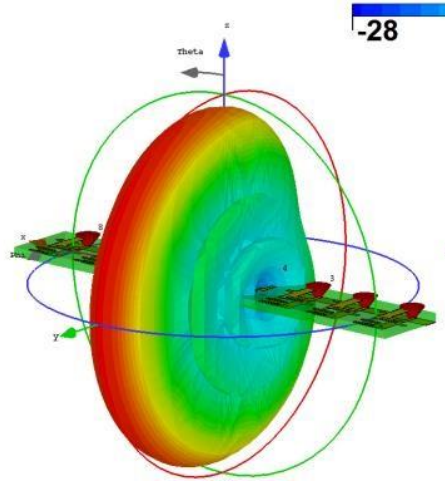

(a)

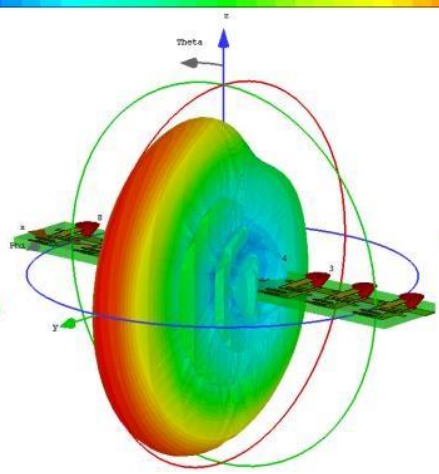

(b)

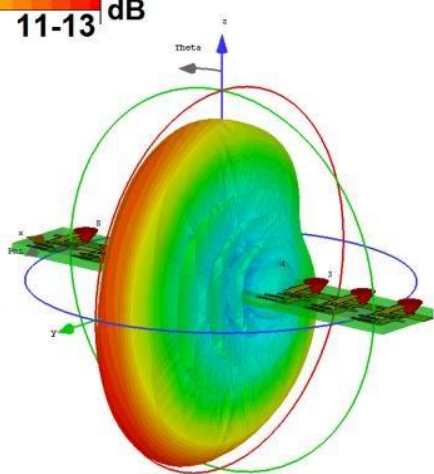

(c)

Fig. 5. Radiation patterns of the $5 \mathrm{G}$ antenna array at (a) $24 \mathrm{GHz}$, (b) $30 \mathrm{GHz}$, and (c) $35 \mathrm{GHz}$.

Figure 6 illustrates the 3D radiation beam-steering purpose of the created phased array 5G antenna with directivity values at the middle frequency $(30 \mathrm{GHz})$. As can be observed, sufficient radiation beams with high directivities are obtained in the scanning angle of $0^{\circ} \sim 60^{\circ}$. It can be witnessed that the projected model structures appropriate radiation bemas with low side lobes. 
More than $11 \mathrm{~dB}$ IEEE gain degrees are accomplished for the examining range of 0 60 degrees at the selected frequency [28-30].

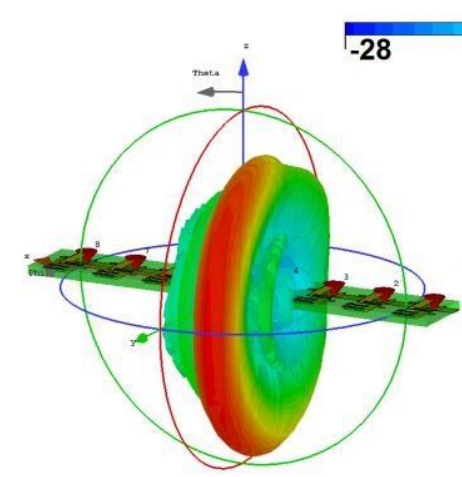

(a)

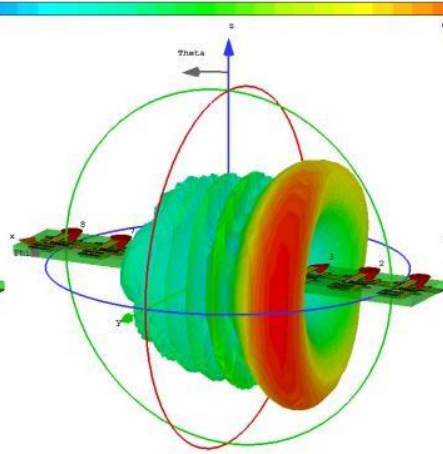

(b)

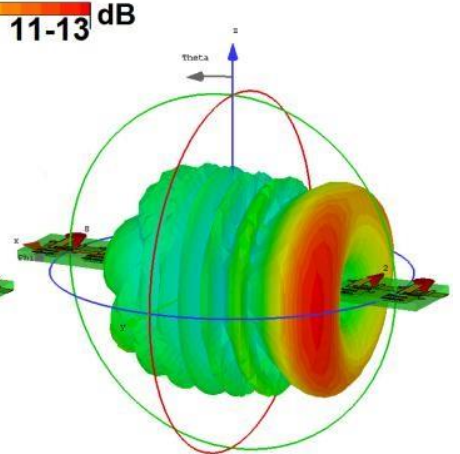

(c)

Fig. 6. $3 \mathrm{D}$ beams of the proposed design at (a) $0^{\circ}$, (b) $30^{\circ}$, and (c) $60^{\circ}$.

\section{User-Impact Imvestigation}

The antenna characteristics in the presence of the human body including the consumer-hand and consumer-head can be reduced [31-33]. This also depends on the distance and placement of the antenna. The placement of the proposed array in the mainboard of the 5G smartphone with a size of $\mathrm{W}_{\mathrm{x}} \times \mathrm{L}_{\mathrm{x}}$ is shown in Fig. 7 (a). In addition, Figure 7 (b) represents the data-mode when the user-hand touche the smartphone in data-mode. Figure 8 investigated the accomplishment of the antenna in data-mode for various examining angles. As demonstrated, the antenna has decent radiation beams and beam-steering function at different scanning angles. This might be due to miniaturized and compact sizes of the employed element which not covered by user-hand [3435].

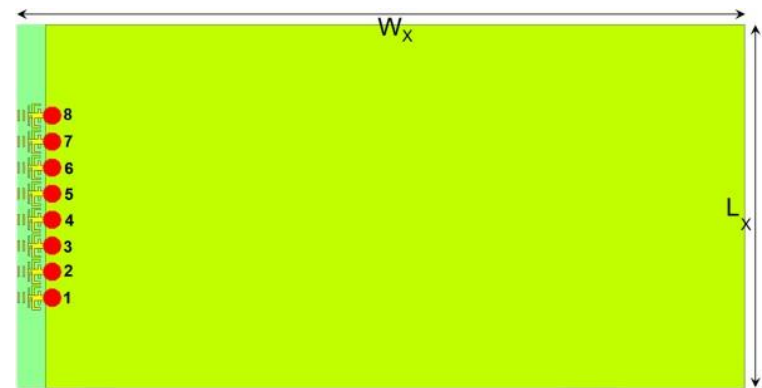

(a)

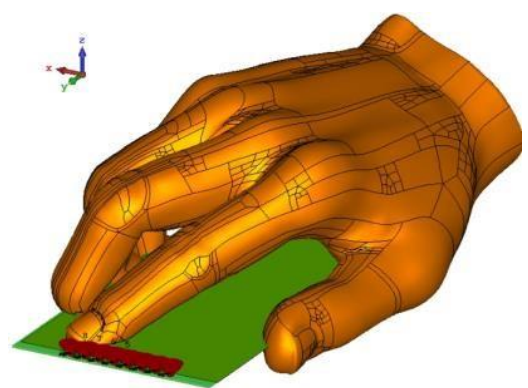

(b)

Fig. 7. (a) $5 \mathrm{G}$ smartphone antenna array design and (b) its placement in Data-mode. 


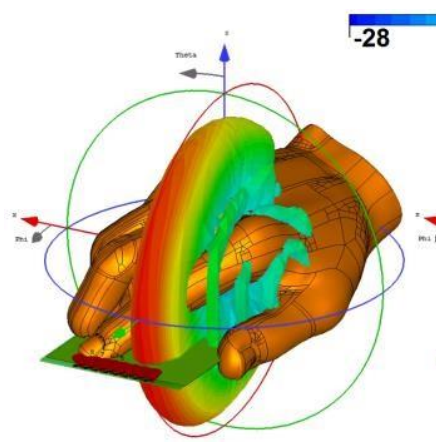

(a)

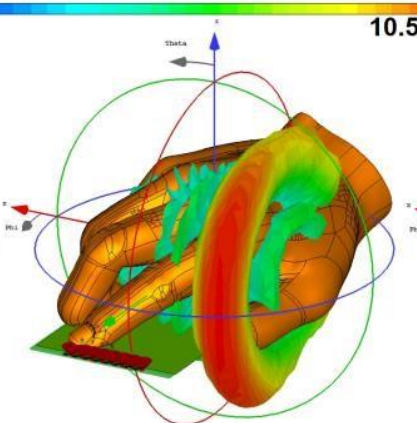

(b)

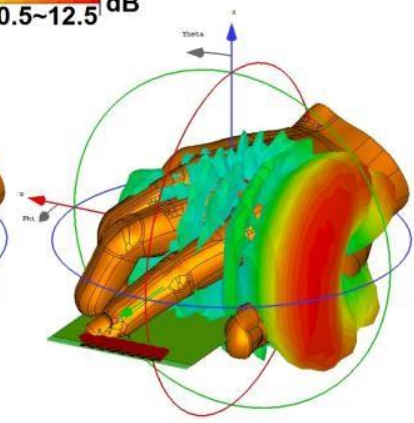

(c)

Fig. 8. 3D radiation beams of the smartphone antenna design in data-mode at (a) $0^{\circ}$, (b) $30^{\circ}$, and (c) $60^{\circ}$.

\section{Conclusion}

This document proposed a broadband phased array with compact antenna elements for 5G cellular phone communications. The configuration of the projected design is composed of eight modified dipole antennas with a pair of directors arranged in a $1 \times 8$ linear form on the top section of smartphone PCB. Simulated outcomes of the antenna's fundamental characteristics have been examined. The outcomes show that the proposed phased array exhibits sufficient characteristics over its operation band, which can be suitable for multi-mode communications in $5 \mathrm{G}$ systems. The antenna also exhibit sufficient performance in data-mode

\section{References}

[1] Gupta, P.: Evolvement of mobile generations: $1 \mathrm{G}$ to 5G. International Journal for Technological Research in Engineering. Vol. 1, pp. 152-157(2013)

[2] Wang, Y. et al.: 5G mobile: Spectrum broadening to higher-frequency bands to support high data rates. IEEE Vehicular Technology Magazine. Vol. 9, pp. 39-46 (2014)

[3] Parchin, N. O. et al.: Microwave/RF components for 5G front-end systems. Avid Science (2019) [4] Al-Yasir, Y. et al.: New radiation pattern-reconfigurable $60-\mathrm{GHz}$ antenna for $5 \mathrm{G}$ communications. Modern Printed Circuit Antennas. IntechOpen (2019)

[5] Parchin, N. O. Abd-Alhameed, R. A.: A compact Vivaldi antenna array for 5G channel sounding applications. EuCAP, London, UK (2018)

[6] Ojaroudiparchin, N. et al.: Design of Vivaldi antenna array with end-fire beam steering function for 5G mobile terminals", 23rd Telecommunications Forum, Belgrade, Serbia, pp. 587-590 (2015)

[7] Ullah, A. et al.: Coplanar waveguide antenna with defected ground structure for 5G millimeter wave communications. IEEE MENACOMM'19, Bahrain (2019)

[8] Parchin, N. O. et al.: Frequency-switchable patch antenna with parasitic ring load for 5G mobile terminals. International Symposium on Antennas and Propagation (ISAP), Xian, China (2019)

[9] Hong, W. et al.: Design and analysis of a low-profile $28 \mathrm{GHz}$ beam steering antenna solution for future 5G cellular applications. IEEE international microwave symposium, June, Florida (2014)

[10] Ojaroudiparchin, N. et al.: Beam-steerable microstrip-fed bow-tie antenna array for fifth generation cellular communications. EuCAP 2016, Switzerland (2016)

[11] Bai, T. and Heath, R.: Coverage and rate analysis for millimeter wave cellular networks. IEEE Transactions on Wireless Communications. Vol. 14, pp. 110-1114 (2015) 
[12] Zolghadr, J. et al.: UWB slot antenna with band-notched property with time domain modeling based on genetic algorithm optimization. ACES Journal, Vol. 31, pp. 926-932 (2016)

[13] Akbarzadeh, H. et al.: Utilization of protruded strip resonators to design a compact UWB antenna with WiMAX and WLAN notch bands. ACES Journal, Vol. 31, pp. 159-163 (2016)

[14] Siahkal-Mahalle, B. H. et al.: A new design of small square monopole antenna with enhanced bandwidth by using cross-shaped slot and conductor-backed plane. Microwave Opt Technol Lett, vol. 54, pp. 2656-2659 (2012)

[15] Valizade, A. et al.: Band-notch slot antenna with enhanced bandwidth by using $\Omega$-shaped strips protruded inside rectangular slots for UWB applications. Appl. Comput. Electromagn. Soc. (ACES) J., Vol. 27, pp. 816-822 (2012)

[16] Bahmani, M. et al.: A compact UWB slot antenna with reconfigurable band-notched function for multimode applications. ACES Journal, Vol. 13, pp. 975-980 (2016)

[17] Ojaroudi, N.: Circular microstrip antenna with dual band-stop performance for ultra-wideband systems. Microw. Opt. Technol. Lett. Vol. 56, pp. 2095-2098 (2014)

[18] Ojaroudiparchin, N. et al.: Wide-scan phased array antenna fed by coax-to-microstriplines for 5G cell phones. MIKON Conference, Krakow, Poland, May (2016)

[19] Hong, W. et al.: mmWave phased-array with hemispheric coverage for 5th generation cellular handsets. EuCAP, pp. 714-716 (2014)

[20] Ojaroudi, N.: Design of microstrip antenna for 2.4/5.8 GHz RFID applications. German Microwave Conference, GeMic 2014, RWTH Aachen University, Germany, March 10-12 (2014)

[21] Musavand, A. et al.: A compact UWB slot antenna with reconfigurable band-notched function for multimode applications. Appl Comp Electromagn Soc J, Vol. 31, pp. 14-18 (2016)

[22] Chen, Q. et al.: Design considerations for millimeter wave antennas within a chip package. IEEE International Workshop on Anti-counterfeiting, Security, Identification, Xiamen, pp. 13-17 (2007)

[23] Elfergani, I. T.E. et al.: Antenna fundamentals for legacy mobile applications and beyond. Springer Nature, pp. 1-659 (2017)

[24] Bahmani, M. et al.:A compact UWB slot antenna with reconfigurable band-notched function for multimode applications. ACES Journal, Vol. 13, pp. 975-980 (2016)

[25] Ojaroudiparchin, N., Shen, M. and Pedersen, G. F.: MM-wave dielectric resonator antenna (DRA) with wide bandwidth for the future wireless networks. International Conference on Microwaves, Radar and Wireless Communications (MIKON). Poland, May (2016)

[26] Parchin, N. O. et al.: Frequency reconfigurable antenna array for $\mathrm{mm}$-Wave 5G mobile handsets. BroadNets, Faro, Portugal, 19-20 September (2018)

[27] Parchin, N. O.: Low-profile air-filled antenna for next generation wireless systems. Wireless Personal Communications. Vol. 97, pp. 3293-3300 (2017)

[28] Ojaroudiparchin, N. et al.: Design of Vivaldi antenna array with end-fire beam steering function for 5G mobile terminals", 23rd Telecommunications Forum, Belgrade, Serbia, pp. 587-590 (2015)

[29] Ilvonen, J. et al.: Mobile terminal antenna performance with the user's hand. IEEE Antenna and Wreless Propagation Letters. Vol. 10, pp. $772-775$ (2000)

[30] Zhang, S. et al.: Compact beam-steerable antenna array with two passive parasitic elements for 5G mobile terminals at 28 GHz. IEEE Trans. Antennas Propag., Vol. 66, pp. 5193-5203 (2018)

[31] Parchin, N. O. et al.: High-performance Yagi-Uda antenna array for $28 \mathrm{GHz}$ mobile communications," $23^{\text {th }}$ Telecommunications Forum, 25-27 November, Belgrade, Serbia (2019)

[32] Parchin, N. O. et al.: Reconfigurable phased array 5G smartphone antenna for cognitive cellular networks. $23^{\text {th }}$ Telecommunications Forum, 25-27 November, Belgrade, Serbia (2019)

[33] $\mathrm{Pi}, \mathrm{Z}$. and Khan, F.: An introduction to millimeter-wave mobile broadband systems. IEEE Commun. Mag., Vol. 49, pp. 101-107 (2011)

[34] Parchin, N. O. et al.: Frequency reconfigurable antenna array for mmWave 5G mobile handsets, BroadNets, Faro, Portugal, 19-20 September (2018) 
[35] Parchin, N. O. et al.: A substrate-insensitive antenna array with broad bandwidth and high efficiency for 5G mobile terminals," Photonics \& Electromagnetics Research Symposium (PIERS), Xiamen, China (2019) 